\title{
Fibroblast Growth Factor 23 and Acute Kidney Injury
}

\author{
Javier A. Neyra ${ }^{1}$, Orson W. Moe ${ }^{1,2,3}$, and Ming Chang $\mathrm{Hu}^{1,3,{ }^{*}}$ \\ ${ }^{1}$ Department of Internal Medicine, University of Texas Southwestern Medical Center, Dallas, \\ Texas, USA \\ ${ }^{2}$ Department of Physiology, University of Texas Southwestern Medical Center, Dallas, Texas, \\ USA \\ ${ }^{3}$ Charles and Jane Pak Center for Mineral Metabolism and Clinical Research, University of Texas \\ Southwestern Medical Center, Dallas, Texas, USA
}

\section{Abstract}

Fibroblast growth factor 23 (FGF23) which is produced in bone, participates in the maintenance of phosphate metabolism and can serve as a biomarker for cardiovascular adverse outcomes in patients with chronic kidney and end-stage renal disease. Circulating FGF23 rapidly increases after acute kidney injury (AKI), preceding other known markers such as neutrophil gelatinaseassociated lipocalin and serum creatinine. The increase in FGF23 in AKI appears to be independent of parathyroid hormone, vitamin D signaling pathways and dietary phosphate. The potential mechanisms include: 1) increased production of FGF23 in the bone by yet-to-beidentified factors; 2) ectopic production of FGF23 by injured renal tubules; and 3) decreased renal clearance of circulating FGF23. Circulating FGF23 determined by intact FGF23 enzyme-linked immunosorbent assay (ELISA) is a more reliable biomarker of AKI than FGF23 C-terminal ELISA (a mixed readout of C-terminal fragment and intact FGF23). Given that FGF23 can be ectopically expressed in differentiated renal tubules and iron modulates FGF23 metabolism, an effect of iron on FGF23 expression in renal tubules is conceivable but remains to be confirmed. More clinical and experimental studies are required to validate the use of circulating FGF23 as a biomarker for the early identification of AKI and prediction of short- and long-term adverse outcomes post-AKI. More importantly, the biologic effect of increased FGF23 in AKI needs to be defined.

\section{Keywords}

acute kidney injury; bone; FGF23; iron; Klotho

\section{Introduction}

The Fibroblast growth factor (FGF) 19 subfamily consists of three members FGF19(15), FGF21 and FGF23, and participates in regulation of energy homeostasis, bile secretion, and

*Corresponding author: Ming Chang Hu, Department of Internal Medicine, Charles and Jane Pak Center for Mineral Metabolism and Clinical Research, UT Southwestern Medical Center, 5323 Harry Hines Blvd, Dallas, TX, 75390-885 USA, Telephone:

1-214-648-9797, Fax: 1-214-648-5652, ming-chang.hu@utsouthwestern.edu. 
mineral and bone metabolism as endocrine hormones [1] which differ from canonic FGF families that typically serve as autocrine/paracrine growth factors to modulate organ morphogenesis [2]. A unique structural feature of the FGF19 subfamily members is their lack of heparin-binding domain that is preserved in all paracrine/autocrine FGFs impeding the capture in extracellular matrices and believed to enable their endocrine release. The Klotho family members of transmembrane proteins function as co-receptors to enhance the binding of the endocrine FGFs to FGFRs through formation of 2Klotho/2FGF/2FGFR ligand-receptor complex, and subsequent activation of FGF signal transduction at their target organs [3-5].

FGF23 was identified as a phosphaturic hormone in 2000 [6]. FGF23, produced in bone, controls renal phosphate reabsorption [7, 8], modulates the production of parathyroid hormone (PTH) [9] and 1,25-(OH) $)_{2}$-vitamin D $[9,10]$ and participates in mineral homeostasis [11-13]. Since its discovery, the study of its role in mineral homeostasis has been the main focus of FGF23 research. FGF23 is dramatically increased in chronic kidney disease (CKD) and end-stage renal disease (ESRD) and has been proposed as a biomarker for adverse outcomes in patients with CKD and ESRD [14-18], but neither an adaptive or pathogenic role of FGF23 in CKD has been definitively proven. FGF23 circulates as the full length intact protein and as a C-terminal fragment after proteolytic cleavage. FGF23 Cterminal enzyme-linked immunosorbent assay (ELISA) yields the sum of the C-terminal fragment and intact FGF23, because the antibodies detect epitopes within the C-terminus of FGF23 [19]. Therefore, "FGF23 C-terminal ELISA" refers to the sum of C-terminal fragment (reported in RU/ml) and intact FGF23 throughout this manuscript; which constitutes the bulk of the clinical data.

Alpha-Klotho (aKlotho) functions as an obligate co-receptor to form a constitutive binary complex with FGFR1c, FGFR3c and FGFR4 to increase the affinity of these FGFRs selectively to FGF23 and not to other FGFs [20, 21]. The canonical FGF23 signaling pathway obligates the presence of aKlotho. Some have suggested that FGF23 may act independently of aKlotho; particularly when present in supra-physiologic concentrations $[14,22]$.

In the current era of heightened awareness of the dire need for early diagnosis of AKI, FGF23 has been touted as a potential marker of the complex AKI syndrome. This manuscript will review the current data regarding FGF23 in AKI, including the understanding of mechanisms of FGF23 level changes in AKI and the potential clinical utility of FGF23 as an early biomarker of AKI.

\section{Circulating FGF23 in acute kidney injury}

Over the last decade, the bulk of clinical observations and experimental studies have showed that FGF23 is a biomarker for CKD as it rises earlier than alterations of other serum parameters such as creatinine $\left(\mathrm{S}_{\mathrm{Cr}}\right), 1,25-(\mathrm{OH})_{2}$ vitamin $\mathrm{D}, \mathrm{PTH}$ and phosphate [23-25]. Moreover, FGF23 may also be a predictor for poor outcomes in CKD as increased FGF23 is associated with rapid progression to ESRD and increased cardiovascular morbidity and mortality [14, 26-29]. In contrast to risk-stratification of cardiovascular events and 
prediction of CKD progression, there are few studies addressing the changes of circulating FGF23 levels in patients with AKI [30-35]. We have summarized the studies to date in Table 1.

The first evidence of elevated FGF23 levels in patients with AKI was a case report by Leaf and coworkers [36]. Subsequently, a small-scale study of 12 AKI patients and 8 non-AKI controls from a medical intensive care unit (ICU) confirmed this observation [30]. AKI was adjudicated by two nephrologists based on Acute Kidney Injury Network (AKIN) Stage I criteria [37] and most of the AKI cases were deemed to be due to acute tubular necrosis. This cross-sectional study showed higher circulating levels of FGF23 by FGF23 C-terminal ELISA in patients with AKI (median levels: $1948 \mathrm{RU} / \mathrm{ml}$ ) than in controls without AKI (median levels: $252 \mathrm{RU} / \mathrm{ml}$ ). This elevation in combined intact and C-terminal fragment FGF23 was not associated with increased serum phosphate [30]; which by itself does not rule out phosphate overload [36]. Due to its retrospective nature, this study was not longitudinal and the plasma samples for FGF23 measurements were obtained at different time points for AKI cases and controls (closest to the peak $\mathrm{S}_{\mathrm{Cr}}$ and immediately after admission, respectively). No information on the time profile of FGF23 levels was available. In addition to patients with AKI in the medical ICU, high FGF23 C-terminal ELISA-based levels were also seen in patients who developed AKI after cardiac surgery [34], which provided a clearer time profile of FGF23 level changes pre-, intra-, and post-operation (Table 1). FGF23 C-terminal ELISA measurements significantly increased starting 24 hours after cardiac surgery in all patients who subsequently met AKI criteria ( $250 \%$ increase in $\mathrm{S}_{\mathrm{Cr}}$ from baseline) and continued to rise by 48 hours which was the latest time-point in that study. The same researchers used a murine AKI model induced by folic acid to define the time profile of FGF23 levels and found that the levels of combined C-terminal fragment and intact FGF23 determined by C-terminal ELISA kit started to increase at 1 hour, whereas intact FGF23 increased at 2 hours after AKI induction [34]. Because intact FGF23 was not measured at 1 hour post-AKI induction, it is not clear whether the increase in C-terminal fragment of FGF23 rises before intact FGF23.

\section{High circulating FGF23 is associated with higher risk of AKI}

Ali and coworkers conducted a study using a nested case-control design and performed plasma FGF23 C-terminal ELISA in 19 children who underwent cardiopulmonary bypass surgery. Children with CKD were excluded and both pre- and post-operative plasma samples were analyzed [33]. Patients who developed AKI following cardiac surgery had elevated FGF23 C-terminal ELISA readings both pre- and post-operatively compared with children who did not develop AKI (Table 1). If the pre-operative value was $>86 \mathrm{RU} / \mathrm{ml}$, the relative risk of developing AKI was two-fold greater than in children with pre-operative values below that cut-off. The receiver operating curve showed an impressive area under the curve of 0.84 for the prediction of AKI following cardiac surgery using this cut-off. This small pilot study showed that pre-operative circulating levels of combined C-terminal fragment and intact FGF23 may serve as a predictor for the development of AKI after cardiac surgery in pediatric patients. The biologic basis for this finding is unknown and this empiric observation requires confirmation. 
In the folic acid-induced murine AKI model, a significant increase in plasma FGF23 Cterminal ELISA signal was detected as early as 1 hour following the kidney insult and reached an 18-fold increase from baseline at 24 hours; while plasma intact FGF23 and phosphate were significantly higher at 2 hours and neutrophil gelatinase-associated lipocalin, a known kidney injury biomarker, lagged behind at 6 hours compared with controls. There was a strong correlation between FGF23 C-terminal and intact FGF23 ELISA-based values $\left(R^{2}=0.97\right)$ suggesting that in this animal model, the augmentation of circulating FGF23 was first driven by the C-terminal fragment at early phase and possibly later by intact FGF23 following the kidney insult (Table 1) [34]. The exact time profile of FGF23 C-terminal fragment vs. intact FGF23 in AKI still needs to be defined.

To identify novel risk factors for AKI hospitalizations which frequently occur in the elderly, Brown and colleagues screened single measurements of plasma FGF23 C-terminal ELISA in 3241 community-dwelling elderly individuals without significant pre-existing kidney disease in the cohort of the Cardiovascular Health Study and analyzed the association of plasma FGF23 (sum of intact and C-terminal fragment) at study entry with the annual AKI event rate. After a median 10-year follow-up, 119 (3.7\%) subjects were hospitalized because of AKI. Adjudication of AKI hospitalizations was based on hospital discharge International Classification of Disease, Ninth Revision, Clinical Modification (ICD-9-CM) diagnosis codes for AKI as the primary diagnosis. The highest quartile of signal from FGF23 Cterminal ELISA (>100 RU/ml) was independently associated with a 2-fold higher risk of AKI hospitalization when the lowest quartile was used as the reference of comparison and after adjustment for kidney disease parameters such as estimated glomerular filtration rate (eGFR) and urine albumin-to-creatinine ratio (Table 1). A similar risk of AKI hospitalization was found in the lowest quartile of eGFR inferred from serum cystatin C. However, no linear relationship (eg, the higher the levels, the higher the risk) between FGF23 levels and AKI hospitalization risk was found when FGF23 C-terminal ELISA-based levels were 54-100 RU/ml, particularly after adjustment for cardiovascular and kidney disease parameters as confounders. Only FGF23 C-terminal ELISA signal >100 RU/ml was found to be consistently and independently associated with a higher risk of AKI hospitalization in this community-dwelling elderly population [35]. Again, the biologic significance of this finding is unclear. It is conceivable that FGF23 may be a covariate of factors that were not accounted for in the adjustment of confounders.

\section{High circulating FGF23 and adverse outcomes in acute kidney injury}

One case-control study of 30 AKI patients and 30 non-AKI controls performed FGF23 Cterminal ELISA at enrollment (within 24 hours of AKI onset) and 5 days later [31]. This study showed that FGF23 C-terminal ELISA-based levels at enrollment were significantly higher in AKI patients $(1471 \mathrm{RU} / \mathrm{ml})$ than in controls $(263 \mathrm{RU} / \mathrm{ml})$ (Table 1). The levels were reduced to $459 \mathrm{RU} / \mathrm{ml}$ at day 5 in patients with $\mathrm{AKI}$, characterizing the transient nature of the elevation. Interestingly, the plasma FGF23 C-terminal ELISA signal was higher in both AKI cases and controls if the subjects were in the medical ICU (1893 and $322 \mathrm{RU} / \mathrm{ml}$, respectively) when compared to those in the hospital wards (710 and $205 \mathrm{RU} / \mathrm{ml}$, respectively). The finding of higher FGF23 in non-AKI subjects in the ICU than those in the general wards, indicates that the elevation of FGF23 in critically ill non-surgical patients is 
independent of AKI episode, which was similar to that in non-AKI subjects post cardiac surgery [34]. This observation highlights the potential contribution of increased systemic inflammation or stress typically seen in critical illness or major surgery to the elevation of either intact or C-terminal fragment of FGF23 in the circulation; or this may be due to subtle sub-clinical renal hypoperfusion or toxicity. Furthermore, the fact that non-AKI FGF23 levels may differ based on the severity of the underlying illness poses a formidable challenge for validation of FGF23 as a biomarker of AKI, as subsets of patients in different clinical contexts may have different cut-offs for prediction of AKI or adverse outcomes post-AKI.

Circulating FGF23 by C-terminal ELISA was significantly higher in patients who died or required renal replacement therapy (RRT): $3376 \mathrm{RU} / \mathrm{ml}$ vs. $404 \mathrm{RU} / \mathrm{ml}, p<0.001$, respectively. Approximately $70 \%$ of AKI patients in the highest tertile at enrollment died or required RRT [31]. Circulating FGF23 C-terminal ELISA-based levels positively correlated with the severity of sepsis; because the highest plasma levels were found in patients with septic shock, and plasma levels in patients with uncomplicated sepsis did not differ from those without sepsis (Table 1) [32]. None of these associations can distinguish co-variation (marker of disease severity) vs. causality and thus far, even the positive association is confounded by whether the intact or C-terminal fragment of FGF23 is varying with the AKI state, or the severity of the underlying illness, as AKI patients are almost inevitably much sicker.

\section{Mechanisms of increased circulating FGF23 in acute kidney injury}

Given that circulating FGF23 increases rapidly after AKI, what is the origin of increased circulating FGF23 while mineral homeostasis is still mostly intact? Christov and colleagues explored the source of increased FGF23 levels in a murine folic acid model of AKI and found that FGF23 protein expression in the bone was 2-fold elevated in AKI mice, which suggests that bone may be the source of circulating FGF23 in AKI [34]. In vivo studies in genetically manipulated mice with interruption of PTH and vitamin D signal pathways demonstrated that increased bone FGF23 production in AKI is independent of the PTH and vitamin D signal pathways. Furthermore, low dietary phosphate intake induced pre-AKI hypophosphatemia, attenuated but not abolished post-AKI hyperphosphatemia, and did not ameliorate kidney damage nor reduced circulating FGF23 levels in the murine folic acid model [34]. But this experiment did not examine FGF23 production in bone, therefore the role of phosphate in stimulation of FGF23 production in bone cannot be ruled out, especially because plasma phosphate was still elevated post-AKI in mice fed a low phosphate diet. After human intact FGF23 protein was injected into mice, exogenous human FGF23 was determined by human C-terminal ELISA. The removal of exogenous human FGF23 (the sum of C-terminal fragment and intact FGF23) from the circulation was slower in AKI mice than in normal mice (half-life 33 vs. 22 minutes, $p=0.01$, respectively) indicating that impaired clearance of FGF23 from the circulation via renal or other pathways also contributes to the increased circulating FGF23 levels [34]. Because we do not know whether the high FGF23 C-terminal ELISA signal in the circulation is intact FGF23 or C-terminal fragment, we cannot conclude whether high circulating FGF23 results from a decline in 
renal clearance of intact FGF23 and/or FGF23 C-terminal fragment. Therefore, the renal clearance of circulating FGF23 in AKI remains to be further explored.

Another important question is whether there is ectopic expression and secretion of FGF23 outside the bone. Zanchi and coworkers found FGF23 mRNA in renal proximal and distal tubules of Zucker diabetic fatty (ZDF) rats, a model of metabolic syndrome; but not in the kidney of lean rats. With aging, circulating FGF23 C-terminal ELISA-based levels significantly increased, while aKlotho mRNA and protein decreased in the kidneys of ZDF rats. In this experimental model, angiotensin converting enzyme inhibition reduced proteinuria and renal injury, normalized serum phosphate, attenuated renal FGF23 transcript up-regulation and improved aKlotho expression. These experiments in intact animals cannot establish a causal relationship of reduction in FGF23 levels or restoration of aKlotho with improvement in renal function and morphology [38].

Patients with autosomal dominant polycystic kidney disease (ADPKD) have higher circulating FGF23 than patients with CKD from other causes matched for eGFR [39]. Circulating FGF23 and urinary phosphate excretion are higher in ADPKD patients when compared to non-diabetic early CKD patients and healthy volunteers [40], suggesting that FGF23 bioactivity may be high $[17,39]$. The reason and source of this higher circulating FGF23 was not accounted for. In one rat model of PKD, Spichtig and coworkers found that FGF23 was expressed in the cells lining renal cysts, but did not find differences of FGF23 expression in bone between PKD and control rats. However, the ectopic expression of FGF23 in the kidney does not appear to be the principal contributor to increased circulating intact FGF23, because high circulating intact FGF23 preceded the appearance of renal FGF23 [41]. FGF23 renal clearance was not measured.

In summary, the proposed mechanisms of increased circulating FGF23 in AKI can be a combination of: 1) increased bone production of FGF23 which is not regulated by PTH or vitamin $\mathrm{D}$ signaling, nor - although not fully proven - by restriction of dietary phosphate intake; 2) increased ectopic production of FGF23 probably from renal tubules under intrinsic pathologic injury; and 3) decreased renal clearance of circulating FGF23 (Figure 1). Whether proteolytic cleavage of the bioactive FGF23 molecule (intact FGF23) is decreased in AKI is not known. The 1-hour delayed signal of intact FGF23 when compared with FGF23 C-terminal ELISA (the sum of C-terminal fragment and intact FGF23) in experimental AKI rather supports that there is a transient up-regulation of proteolytic cleavage of intact FGF23 in a very early stage of AKI, which may be a general phenomenon in response to non-specific stress.

\section{Effect of iron status on FGF23 metabolism in acute kidney injury}

Iron is an essential cofactor for a variety of fundamental cellular processes and is indispensable for living organisms [42]. On the other hand, iron is also a potentially hazardous bio-metal, because it catalyzes the propagation of reactive oxygen species and free radicals to induce oxidative stress and cause tissue injury [43, 44]. Both iron deficiency and iron overload are well-known to be disease-causing, and body and serum iron concentration and iron metabolism are tightly regulated [43, 44]. 
An interesting aspect of FGF23 metabolism emerged recently. Iron modifies FGF23 metabolism in patients with or without kidney disease [45-48], but whether iron deficiency or iron supplementation induces FGF23 production is still inconclusive. Iron repletion was associated with increased intact FGF23, decreased serum phosphate and increased risk of bone fracture in iron-deficient patients [49-51]. Wolf and coworkers showed that women with iron deficiency anemia had elevated levels of FGF23 C-terminal ELISA but not intact FGF23 [52]. The FGF23 response to iron deficiency was shown to cause hypophosphatemia in patients with autosomal dominant hypophosphatemic rickets (ADHR) but not in wild-type FGF23 patients [45, 52]. These clinical observations were confirmed in a genetically engineered mouse model with the ADHR mutation in FGF23 knocked in, and fed an irondeficient diet $[48,53]$. A model is proposed where iron deficiency stimulates FGF23 transcription and production in osteocytes. Simultaneously, wild-type FGF23 protein cleavage is also increased, thus abolishing elevation of intact FGF23 and high FGF23 bioactivity. ADHR FGF23 protein is resistant to the yet-to-be-identified protease and consequently circulating intact FGF23 increases along with its bioactivity. They further hypothesize that CKD patients who have iron deficiency demonstrate increased FGF23 production and decreased FGF23 cleavage, that may mimic the FGF23 profile in ADHR [45].

Several small-scale clinical observations have revealed inconsistent results about serum iron status in AKI [54, 55]. Iron accumulation in the kidney has been described in AKI patients and experimental AKI animals [56], and can activate oxidative stress [57] and stimulate the release of monokines and cytokines from renal tubules [58]. Given that FGF23 may be ectopically expressed in differentiated renal tubules $[39,41]$ and iron modulates FGF23 metabolism, an iron effect on FGF23 expression in renal tubules during subclinical AKI is conceivable, but remains to be confirmed, to hopefully open a novel avenue to regulate FGF23 expression and subsequently treat AKI through renal iron control. However, a causeand-effect relationship must be first established.

\section{Where do we stand now with FGF23 in AKI?}

In the past decade, an impressive array of clinical and basic data have emerged and tremendous efforts have been made to transform FGF23 from a regulator of mineral metabolism to a biomarker for predicting adverse outcomes in CKD/ESRD patients and a pathogenic intermediate for cardiovascular disease, bone disease and secondary hyperparathyroidism in CKD/ESRD. Compared to the extensive work on FGF23 in CKD, the research of FGF23 in AKI is still very much in its infancy. Translating pre-clinical research on FGF23 into clinical studies is needed: 1) to determine the potential utility of FGF23 as an early biomarker of AKI; 2) to determine its role as a predictor of adverse outcomes post-AKI; and 3) to explore its potential role as an adverse hormone worthy of being a therapeutic target. Several specific issues should be highlighted.

\section{Do we have a reliable assay to monitor FGF23 levels and bioactivity now?}

There are several naturally occurring fragments of FGF23 (intact, N-terminal and C-terminal peptides) in the circulation. The FGF23 bioactivity is conferred only by intact FGF23 and by C-terminal peptide which competitively counteracts the intact FGF23 activity when present 
in high enough levels [59]. The current FGF23 C-terminal ELISA kit [60] only provides mixed readout of intact plus C-terminal fragments of FGF23, instead of absolute levels of each, and appears to be the assay of choice perhaps due to cost. Given that there is evidence of dissociation of FGF23 antigenic levels from its bioactivity [61], it is also important to have an FGF23 activity assay. While measurement of activation of FGFR/aKlotho downstream signaling is a viable assay in the research lab, there is no fast and high throughput assay for FGF23 bioactivity for clinical use at the moment. Furthermore, the above mentioned assay cannot detect any "off target" effects of FGF23. Some investigators have proposed the use of the ratio of intact FGF23 and FGF23 C-terminal ELISA (the sum of C-terminal fragment and intact FGF23) as a surrogate to assess FGF23 bioactivity [23, 45], but it is still not easy at the moment to achieve this since there is no simultaneous measurement of both in the same sample and conversion of values between the two commercial kits is not easy. Before FGF23 is considered a biomarker to identify or riskstratify AKI patients early, the establishment of a reliable assay for the quantification of absolute levels of each fragment of FGF23 and its bioactivity is desirable.

\section{Which is better to monitor, C-terminal or intact FGF23?}

In addition to different biologic activity of these two polypeptides as mentioned above, the response of C-terminal fragment and intact FGF23 to acute stress and tissue injury appears to be distinct. One prospective study examined circulating FGF23 levels in patients who underwent hip arthroplasty and found elevated FGF23 by C-terminal ELISA independent of post-operative AKI, but no change in intact FGF23 levels [62], implying that the increase in signal in FGF23 C-terminal ELISA was due to the C-terminal fragment. Similar findings were found in a case-control cohort examining AKI and non-AKI patients after cardiac surgery [34]. Non-AKI patients had a transient 1- to 2-fold increase in circulating FGF23 Cterminal ELISA-based levels only within 24 hours following cardiac surgery, indicating that FGF23 may function as an acute-phase reactant after exposure to the operative stress. This concept was further confirmed by one experimental study showing elevation of FGF23 Cterminal ELISA signal in normal rats within 2 hours after animal preparation without subsequent surgery. Further analysis showed that the increased C-terminal FGF23 level based on C-terminal ELISA was independent of use of anesthetics [63]. The significant increase in FGF23 C-terminal ELISA signal in animals without any surgical intervention within a short experimental period should alert one to cautiously interpret changes of circulating FGF23 using the C-terminal ELISA in acute maneuvers. Furthermore, these observations exposed the different incremental response of circulating FGF23 in critical illness independent of the occurrence of AKI. Whether the C-terminal fragment acts as an acute-phase reactant under stressful conditions or reflects subtle renal hypoperfusion, and intact FGF23 is a true marker of renal injury, remains to be explored. We hypothesize, based on the above described mechanisms, that while intact FGF23 increases later than FGF23 Cterminal ELISA signal, it may serve as a more specific predictor of renal pathology rather than a general state of acute stress and inflammation, and a better prognostic factor of adverse events post-AKI.

No doubt the currently available small size and pilot clinical studies provide stimulating thoughts that early elevation of circulating FGF23 measured by C-terminal ELISA (the sum 
of C-terminal fragment and intact FGF23) is associated with subsequent AKI or adverse outcomes post-AKI in short-term follow-up. We are in need of larger longitudinal studies to provide full time profiles of circulating FGF23 comparing both C-terminal and intact assays in the course of AKI and even during AKI transition to CKD. We also need an accurate way of simultaneously measuring the molar amounts and ratio of the C-terminal fragment and intact FGF23.

\section{Can we manipulate FGF23 levels or activity to treat kidney disease?}

The potential utility of FGF23 antagonism in CKD has been proposed and tested in animal experiments but still remains controversial. Theoretically, three types of reagents can be used to block or suppress FGF23 activity: small molecule inhibitors of FGF23 binding or signaling [64], neutralizing anti-FGF23 antibodies [65] and C-terminal fragment of FGF23 [59]. The therapeutic potential of these therapies has been described in animal studies and small-scale phase I clinical trials in FGF23-related hypophosphatemic diseases [64, 65]. But the effect of FGF23 antagonism in CKD is still far from conclusive and very much under debate $[14,22,66,67]$. A very fundamental unanswered question being, "is the high FGF23 in CKD a mere biomarker, an adaptive compensation, or a maladaptive pathogenic derangement?" Although the consensus favors the latter, it is still not proven and lacks a mechanistic model. If elevated FGF23 is a pathogenic factor in AKI, one will need a "smart" blocker to selectively inhibit the pathologic effect of FGF23, and preserve its physiologic action, an effort that will not be realized unless we have a better understanding of FGF23 biology and pathophysiology.

Iron may be a potent regulator of FGF23 metabolism even though the context, purpose and mechanism of regulation are still elusive at the moment. More preclinical and clinical studies are needed to determine what the iron status is in the injured kidney or bone, and whether iron replacement and which iron formulation will reduce FGF23, and of course to determine whether such maneuvers can attenuate kidney damage or improve long-term outcomes such as retardation of AKI progression to CKD or amelioration of CKD-MBD.

In conclusion, it is presently too premature to consider incorporating circulating FGF23 measurement into the routine AKI testing panel. More work is required to standardize assays to differentiate between C-terminal fragment and intact FG23, and then evaluate the clinical utilization of FGF23 as an early biomarker for AKI or predictor for adverse outcomes postAKI. In addition to establishing the diagnostic and prognostic utility, the pathophysiology underlying the cause and the impact of FGF23 elevation need to be elucidated.

\section{Acknowledgments}

The authors are supported by the National Institutes of Health (R01-DK091392, R01-DK092461), the George M. O'Brien Kidney Research Center at UT Southwestern Medical Center (P30-DK-07938), the Simmons Family Foundation, and the Charles and Jane Pak Foundation. JAN is supported by the Ben J. Lipps Research Fellowship Program of American Society of Nephrology Foundation for Kidney Research, and the Truelson Fellowship Fund at the Charles and Jane Pak Center of Mineral Metabolism and Clinical Research. 


\section{References}

1. Hu MC, Shiizaki K, Kuro-o M, Moe OW. Fibroblast growth factor 23 and Klotho: physiology and pathophysiology of an endocrine network of mineral metabolism. Annu Rev Physiol. 2013; 75:503533. [PubMed: 23398153]

2. Itoh N, Ornitz DM. Functional evolutionary history of the mouse Fgf gene family. Dev Dyn. 2008; 237:18-27. [PubMed: 18058912]

3. Kurosu H, Choi M, Ogawa Y, Dickson AS, Goetz R, Eliseenkova AV, Mohammadi M, Rosenblatt KP, Kliewer SA, Kuro-o M. Tissue-specific expression of betaKlotho and fibroblast growth factor (FGF) receptor isoforms determines metabolic activity of FGF19 and FGF21. J Biol Chem. 2007; 282:26687-26695. [PubMed: 17623664]

4. Suzuki M, Uehara Y, Motomura-Matsuzaka K, Oki J, Koyama Y, Kimura M, Asada M, KomiKuramochi A, Oka S, Imamura T. betaKlotho is required for fibroblast growth factor (FGF) 21 signaling through FGF receptor (FGFR) 1c and FGFR3c. Mol Endocrinol. 2008; 22:1006-1014. [PubMed: 18187602]

5. Wu X, Lemon B, Li X, Gupte J, Weiszmann J, Stevens J, Hawkins N, Shen W, Lindberg R, Chen JL, Tian H, Li Y. C-terminal tail of FGF19 determines its specificity toward Klotho co-receptors. J Biol Chem. 2008; 283:33304-33309. [PubMed: 18829467]

6. ADHR Consortium. Autosomal dominant hypophosphataemic rickets is associated with mutations in FGF23. Nat Genet. 2000; 26:345-348. [PubMed: 11062477]

7. Gattineni J, Baum M. Regulation of phosphate transport by fibroblast growth factor 23 (FGF23): implications for disorders of phosphate metabolism. Pediatr Nephrol. 2010; 25:591-601. [PubMed: 19669798]

8. Gattineni J, Bates C, Twombley K, Dwarakanath V, Robinson ML, Goetz R, Mohammadi M, Baum M. FGF23 decreases renal NaPi-2a and NaPi-2c expression and induces hypophosphatemia in vivo predominantly via FGF receptor 1. Am J Physiol Renal Physiol. 2009; 297:F282-291. [PubMed: 19515808]

9. Krajisnik T, Bjorklund P, Marsell R, Ljunggren O, Akerstrom G, Jonsson KB, Westin G, Larsson TE. Fibroblast growth factor-23 regulates parathyroid hormone and 1alpha-hydroxylase expression in cultured bovine parathyroid cells. J Endocrinol. 2007; 195:125-131. [PubMed: 17911404]

10. Gattineni J, Twombley K, Goetz R, Mohammadi M, Baum M. Regulation of serum 1,25(OH)2 vitamin D3 levels by fibroblast growth factor 23 is mediated by FGF receptors 3 and 4 . Am J Physiol Renal Physiol. 2011; 301:F371-377. [PubMed: 21561999]

11. Larsson T, Marsell R, Schipani E, Ohlsson C, Ljunggren O, Tenenhouse HS, Juppner H, Jonsson KB. Transgenic mice expressing fibroblast growth factor 23 under the control of the alpha1(I) collagen promoter exhibit growth retardation, osteomalacia, and disturbed phosphate homeostasis. Endocrinology. 2004; 145:3087-3094. [PubMed: 14988389]

12. Bai X, Miao D, Li J, Goltzman D, Karaplis AC. Transgenic mice overexpressing human fibroblast growth factor 23 (R176Q) delineate a putative role for parathyroid hormone in renal phosphate wasting disorders. Endocrinology. 2004; 145:5269-5279. [PubMed: 15284207]

13. Finer G, Price HE, Shore RM, White KE, Langman CB. Hyperphosphatemic familial tumoral calcinosis: response to acetazolamide and postulated mechanisms. Am J Med Genet A. 2014; 164A:1545-1549. [PubMed: 24668887]

14. Faul C, Amaral AP, Oskouei B, Hu MC, Sloan A, Isakova T, Gutierrez OM, Aguillon-Prada R, Lincoln J, Hare JM, Mundel P, Morales A, Scialla J, Fischer M, Soliman EZ, Chen J, Go AS, Rosas SE, Nessel L, Townsend RR, Feldman HI, St John Sutton M, Ojo A, Gadegbeku C, Di Marco GS, Reuter S, Kentrup D, Tiemann K, Brand M, Hill JA, Moe OW, Kuro OM, Kusek JW, Keane MG, Wolf M. FGF23 induces left ventricular hypertrophy. J Clin Invest. 2011; 121:43934408. [PubMed: 21985788]

15. Wolf M. Forging forward with 10 burning questions on FGF23 in kidney disease. J Am Soc Nephrol. 2010; 21:1427-1435. [PubMed: 20507943]

16. Gutierrez OM. Fibroblast growth factor 23 and disordered vitamin D metabolism in chronic kidney disease: updating the "trade-off" hypothesis. Clin J Am Soc Nephrol. 2010; 5:1710-1716. [PubMed: 20507957] 
17. Portale AA, Wolf M, Juppner H, Messinger S, Kumar J, Wesseling-Perry K, Schwartz GJ, Furth SL, Warady BA, Salusky IB. Disordered FGF23 and mineral metabolism in children with CKD. Clin J Am Soc Nephrol. 2014; 9:344-353. [PubMed: 24311704]

18. Pavik I, Jaeger P, Ebner L, Wagner CA, Petzold K, Spichtig D, Poster D, Wuthrich RP, Russmann S, Serra AL. Secreted Klotho and FGF23 in chronic kidney disease Stage 1 to 5: a sequence suggested from a cross-sectional study. Nephrol Dial Transplant. 2013; 28:352-359. [PubMed: 23129826]

19. Jonsson KB, Zahradnik R, Larsson T, White KE, Sugimoto T, Imanishi Y, Yamamoto T, Hampson G, Koshiyama H, Ljunggren O, Oba K, Yang IM, Miyauchi A, Econs MJ, Lavigne J, Juppner H. Fibroblast growth factor 23 in oncogenic osteomalacia and X-linked hypophosphatemia. N Engl J Med. 2003; 348:1656-1663. [PubMed: 12711740]

20. Urakawa I, Yamazaki Y, Shimada T, Iijima K, Hasegawa H, Okawa K, Fujita T, Fukumoto S, Yamashita T. Klotho converts canonical FGF receptor into a specific receptor for FGF23. Nature. 2006; 444:770-774. [PubMed: 17086194]

21. Kurosu H, Ogawa Y, Miyoshi M, Yamamoto M, Nandi A, Rosenblatt KP, Baum MG, Schiavi S, $\mathrm{Hu} \mathrm{MC}$, Moe OW, Kuro-o M. Regulation of fibroblast growth factor-23 signaling by klotho. J Biol Chem. 2006; 281:6120-6123. [PubMed: 16436388]

22. Di Marco GS, Reuter S, Kentrup D, Grabner A, Amaral AP, Fobker M, Stypmann J, Pavenstadt H, Wolf M, Faul C, Brand M. Treatment of established left ventricular hypertrophy with fibroblast growth factor receptor blockade in an animal model of CKD. Nephrol Dial Transplant. 2014; 29:2028-2035. [PubMed: 24875663]

23. Smith ER, McMahon LP, Holt SG. Fibroblast growth factor 23. Ann Clin Biochem. 2014; 51:203227. [PubMed: 24269946]

24. Wan M, Smith C, Shah V, Gullet A, Wells D, Rees L, Shroff R. Fibroblast growth factor 23 and soluble klotho in children with chronic kidney disease. Nephrol Dial Transplant. 2013; 28:153161. [PubMed: 23180879]

25. Isakova T, Wahl P, Vargas GS, Gutierrez OM, Scialla J, Xie H, Appleby D, Nessel L, Bellovich K, Chen J, Hamm L, Gadegbeku C, Horwitz E, Townsend RR, Anderson CA, Lash JP, Hsu CY, Leonard MB, Wolf M. Fibroblast growth factor 23 is elevated before parathyroid hormone and phosphate in chronic kidney disease. Kidney Int. 2011; 79:1370-1378. [PubMed: 21389978]

26. Wolf M, Molnar MZ, Amaral AP, Czira ME, Rudas A, Ujszaszi A, Kiss I, Rosivall L, Kosa J, Lakatos P, Kovesdy CP, Mucsi I. Elevated fibroblast growth factor 23 is a risk factor for kidney transplant loss and mortality. J Am Soc Nephrol. 2011; 22:956-966. [PubMed: 21436289]

27. Six I, Okazaki H, Gross P, Cagnard J, Boudot C, Maizel J, Drueke TB, Massy ZA. Direct, acute effects of Klotho and FGF23 on vascular smooth muscle and endothelium. PLoS One. 2014; 9:e93423. [PubMed: 24695641]

28. Silswal N, Touchberry CD, Daniel DR, McCarthy DL, Zhang S, Andresen J, Stubbs JR, Wacker MJ. FGF23 directly impairs endothelium-dependent vasorelaxation by increasing superoxide levels and reducing nitric oxide bioavailability. Am J Physiol Endocrinol Metab. 2014; 307:E426436. [PubMed: 25053401]

29. Nakano C, Hamano T, Fujii N, Matsui I, Tomida K, Mikami S, Inoue K, Obi Y, Okada N, Tsubakihara Y, Isaka Y, Rakugi H. Combined use of vitamin D status and FGF23 for risk stratification of renal outcome. Clin J Am Soc Nephrol. 2012; 7:810-819. [PubMed: 22362065]

30. Zhang M, Hsu R, Hsu CY, Kordesch K, Nicasio E, Cortez A, McAlpine I, Brady S, Zhuo H, Kangelaris KN, Stein J, Calfee CS, Liu KD. FGF-23 and PTH levels in patients with acute kidney injury: A cross-sectional case series study. Ann Intensive Care. 2011; 1:21. [PubMed: 21906363]

31. Leaf DE, Wolf M, Waikar SS, Chase H, Christov M, Cremers S, Stern L. FGF-23 levels in patients with AKI and risk of adverse outcomes. Clin J Am Soc Nephrol. 2012; 7:1217-1223. [PubMed: 22700885]

32. Leaf DE, Waikar SS, Wolf M, Cremers S, Bhan I, Stern L. Dysregulated mineral metabolism in patients with acute kidney injury and risk of adverse outcomes. Clin Endocrinol (Oxf). 2013; 79:491-498. [PubMed: 23414198] 
33. Ali FN, Hassinger A, Price H, Langman CB. Preoperative plasma FGF23 levels predict acute kidney injury in children: results of a pilot study. Pediatr Nephrol. 2013; 28:959-962. [PubMed: 23314442]

34. Christov M, Waikar SS, Pereira RC, Havasi A, Leaf DE, Goltzman D, Pajevic PD, Wolf M, Juppner H. Plasma FGF23 levels increase rapidly after acute kidney injury. Kidney Int. 2013; 84:776-785. [PubMed: 23657144]

35. Brown JR, Katz R, Ix JH, de Boer IH, Siscovick DS, Grams ME, Shlipak M, Sarnak MJ. Fibroblast growth factor-23 and the long-term risk of hospital-associated AKI among communitydwelling older individuals. Clin J Am Soc Nephrol. 2014; 9:239-246. [PubMed: 24262510]

36. Leaf DE, Wolf M, Stern L. Elevated FGF-23 in a patient with rhabdomyolysis-induced acute kidney injury. Nephrol Dial Transplant. 2010; 25:1335-1337. [PubMed: 20037176]

37. Kellum JA, Lameire N. Diagnosis, evaluation, and management of acute kidney injury: a KDIGO summary (Part 1). Crit Care. 2013; 17:204. [PubMed: 23394211]

38. Zanchi C, Locatelli M, Benigni A, Corna D, Tomasoni S, Rottoli D, Gaspari F, Remuzzi G, Zoja C. Renal expression of FGF23 in progressive renal disease of diabetes and the effect of ACE inhibitor. PLoS One. 2013; 8:e70775. [PubMed: 23967103]

39. Pavik I, Jaeger P, Ebner L, Poster D, Krauer F, Kistler AD, Rentsch K, Andreisek G, Wagner CA, Devuyst O, Wuthrich RP, Schmid C, Serra AL. Soluble klotho and autosomal dominant polycystic kidney disease. Clin J Am Soc Nephrol. 2012; 7:248-257. [PubMed: 22193235]

40. Pavik I, Jaeger P, Kistler AD, Poster D, Krauer F, Cavelti-Weder C, Rentsch KM, Wuthrich RP, Serra AL. Patients with autosomal dominant polycystic kidney disease have elevated fibroblast growth factor 23 levels and a renal leak of phosphate. Kidney Int. 2011; 79:234-240. [PubMed: 20944552]

41. Spichtig D, Zhang H, Mohebbi N, Pavik I, Petzold K, Stange G, Saleh L, Edenhofer I, Segerer S, Biber J, Jaeger P, Serra AL, Wagner CA. Renal expression of FGF23 and peripheral resistance to elevated FGF23 in rodent models of polycystic kidney disease. Kidney Int. 2014; 85:1340-1350. [PubMed: 24402093]

42. Wang J, Pantopoulos K. Regulation of cellular iron metabolism. Biochem J. 2011; 434:365-381. [PubMed: 21348856]

43. Andrews NC. Iron metabolism: iron deficiency and iron overload. Annu Rev Genomics Hum Genet. 2000; 1:75-98. [PubMed: 11701625]

44. Andrews NC. Disorders of iron metabolism. N Engl J Med. 1999; 341:1986-1995. [PubMed: 10607817]

45. Wolf M, White KE. Coupling fibroblast growth factor 23 production and cleavage: iron deficiency, rickets, and kidney disease. Curr Opin Nephrol Hypertens. 2014; 23:411-419. [PubMed: 24867675]

46. Imel EA, Gray AK, Padgett LR, Econs MJ. Iron and fibroblast growth factor 23 in X-linked hypophosphatemia. Bone. 2014; 60:87-92. [PubMed: 24325979]

47. Imel EA, Peacock M, Gray AK, Padgett LR, Hui SL, Econs MJ. Iron modifies plasma FGF23 differently in autosomal dominant hypophosphatemic rickets and healthy humans. J Clin Endocrinol Metab. 2011; 96:3541-3549. [PubMed: 21880793]

48. Farrow EG, Yu X, Summers LJ, Davis SI, Fleet JC, Allen MR, Robling AG, Stayrook KR, Jideonwo V, Magers MJ, Garringer HJ, Vidal R, Chan RJ, Goodwin CB, Hui SL, Peacock M, White KE. Iron deficiency drives an autosomal dominant hypophosphatemic rickets (ADHR) phenotype in fibroblast growth factor-23 (Fgf23) knock-in mice. Proc Natl Acad Sci U S A. 2011; 108:E1146-1155. [PubMed: 22006328]

49. Schouten BJ, Doogue MP, Soule SG, Hunt PJ. Iron polymaltose-induced FGF23 elevation complicated by hypophosphataemic osteomalacia. Ann Clin Biochem. 2009; 46:167-169. [PubMed: 19151167]

50. Yamamoto S, Okada Y, Mori H, Fukumoto S, Tanaka Y. Fibroblast growth factor 23-related osteomalacia caused by the prolonged administration of saccharated ferric oxide. Intern Med. 2012; 51:2375-2378. [PubMed: 22975552] 
51. Schouten BJ, Hunt PJ, Livesey JH, Frampton CM, Soule SG. FGF23 elevation and hypophosphatemia after intravenous iron polymaltose: a prospective study. J Clin Endocrinol Metab. 2009; 94:2332-2337. [PubMed: 19366850]

52. Wolf M, Koch TA, Bregman DB. Effects of iron deficiency anemia and its treatment on fibroblast growth factor 23 and phosphate homeostasis in women. J Bone Miner Res. 2013; 28:1793-1803. [PubMed: 23505057]

53. Clinkenbeard EL, Farrow EG, Summers LJ, Cass TA, Roberts JL, Bayt CA, Lahm T, Albrecht M, Allen MR, Peacock M, White KE. Neonatal iron deficiency causes abnormal phosphate metabolism by elevating FGF23 in normal and ADHR mice. J Bone Miner Res. 2014; 29:361369. [PubMed: 23873717]

54. Davis CL, Kausz AT, Zager RA, Kharasch ED, Cochran RP. Acute renal failure after cardiopulmonary bypass in related to decreased serum ferritin levels. J Am Soc Nephrol. 1999; 10:2396-2402. [PubMed: 10541300]

55. Tuttle KR, Worrall NK, Dahlstrom LR, Nandagopal R, Kausz AT, Davis CL. Predictors of ARF after cardiac surgical procedures. Am J Kidney Dis. 2003; 41:76-83. [PubMed: 12500223]

56. Martines AM, Masereeuw R, Tjalsma H, Hoenderop JG, Wetzels JF, Swinkels DW. Iron metabolism in the pathogenesis of iron-induced kidney injury. Nat Rev Nephrol. 2013; 9:385-398. [PubMed: 23670084]

57. Shah SV, Rajapurkar MM, Baliga R. The role of catalytic iron in acute kidney injury. Clin J Am Soc Nephrol. 2011; 6:2329-2331. [PubMed: 21979910]

58. Johnson AC, Becker K, Zager RA. Parenteral iron formulations differentially affect MCP-1, HO-1, and NGAL gene expression and renal responses to injury. Am J Physiol Renal Physiol. 2010; 299:F426-435. [PubMed: 20504881]

59. Goetz R, Nakada Y, Hu MC, Kurosu H, Wang L, Nakatani T, Shi M, Eliseenkova AV, Razzaque MS, Moe OW, Kuro-o M, Mohammadi M. Isolated C-terminal tail of FGF23 alleviates hypophosphatemia by inhibiting FGF23-FGFR-Klotho complex formation. Proc Natl Acad Sci U S A. 2010; 107:407-412. [PubMed: 19966287]

60. Smith ER, Cai MM, McMahon LP, Holt SG. Biological variability of plasma intact and C-terminal FGF23 measurements. J Clin Endocrinol Metab. 2012; 97:3357-3365. [PubMed: 22689697]

61. Shimada T, Urakawa I, Isakova T, Yamazaki Y, Epstein M, Wesseling-Perry K, Wolf M, Salusky IB, Juppner H. Circulating fibroblast growth factor 23 in patients with end-stage renal disease treated by peritoneal dialysis is intact and biologically active. J Clin Endocrinol Metab. 2010; 95:578-585. [PubMed: 19965919]

62. Goebel S, Lienau J, Rammoser U, Seefried L, Wintgens KF, Seufert J, Duda G, Jakob F, Ebert R. FGF23 is a putative marker for bone healing and regeneration. J Orthop Res. 2009; 27:1141-1146. [PubMed: 19215029]

63. Gravesen E, Hofman-Bang J, Mace ML, Lewin E, Olgaard K. High dose intravenous iron, mineral homeostasis and intact FGF23 in normal and uremic rats. BMC Nephrol. 2013; 14:281. [PubMed: 24373521]

64. Wohrle S, Henninger C, Bonny O, Thuery A, Beluch N, Hynes NE, Guagnano V, Sellers WR, Hofmann F, Kneissel M, Graus Porta D. Pharmacological inhibition of fibroblast growth factor (FGF) receptor signaling ameliorates FGF23-mediated hypophosphatemic rickets. J Bone Miner Res. 2013; 28:899-911. [PubMed: 23129509]

65. Fukumoto S. Anti-fibroblast growth factor 23 antibody therapy. Curr Opin Nephrol Hypertens. 2014; 23:346-351. [PubMed: 24848934]

66. Ketteler M, Biggar PH, Liangos O. FGF23 antagonism: the thin line between adaptation and maladaptation in chronic kidney disease. Nephrol Dial Transplant. 2013; 28:821-825. [PubMed: 23233522]

67. Shalhoub V, Shatzen EM, Ward SC, Davis J, Stevens J, Bi V, Renshaw L, Hawkins N, Wang W, Chen C, Tsai MM, Cattley RC, Wronski TJ, Xia X, Li X, Henley C, Eschenberg M, Richards WG. FGF23 neutralization improves chronic kidney disease-associated hyperparathyroidism yet increases mortality. J Clin Invest. 2012; 122:2543-2553. [PubMed: 22728934] 


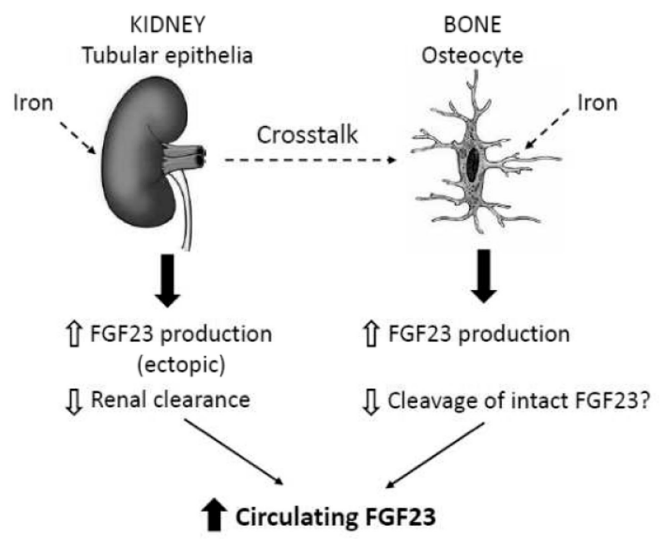

Profile of circulating FGF23

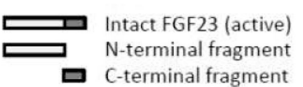
kidney injury

In AKI induced by a variety of renal insults including ischemia, nephrotoxins and metabolic derangements, FGF23 expression is ectopically up-regulated in the renal tubules through yet-to-be-identified mechanism(s). Reduced glomerular filtration rate after AKI episode impairs the clearance of FGF23 from circulation and further increases circulating FGF23. On the other hand, one remote organ, bone, receives signals probably released from injured kidney (dash line) and increases FGF23 production. Dysregulation of iron may also participate in up-regulation of FGF23 in AKI, but there is still lack of direct evidence (dash line). In the circulation, there are intact, N-terminal and C-terminal fragments of FGF23 shown in right panel. The findings that both intact FGF23 and C-terminal FGF23 levels are increased in parallel in established AKI suggested that the major fraction of an increased circulating FGF23 is an intact FGF23, which presumably results from a decline in cleavage of intact FGF23. Impaired intact FGF23 degradation will slow down and further increase circulating FGF23 in AKI. 


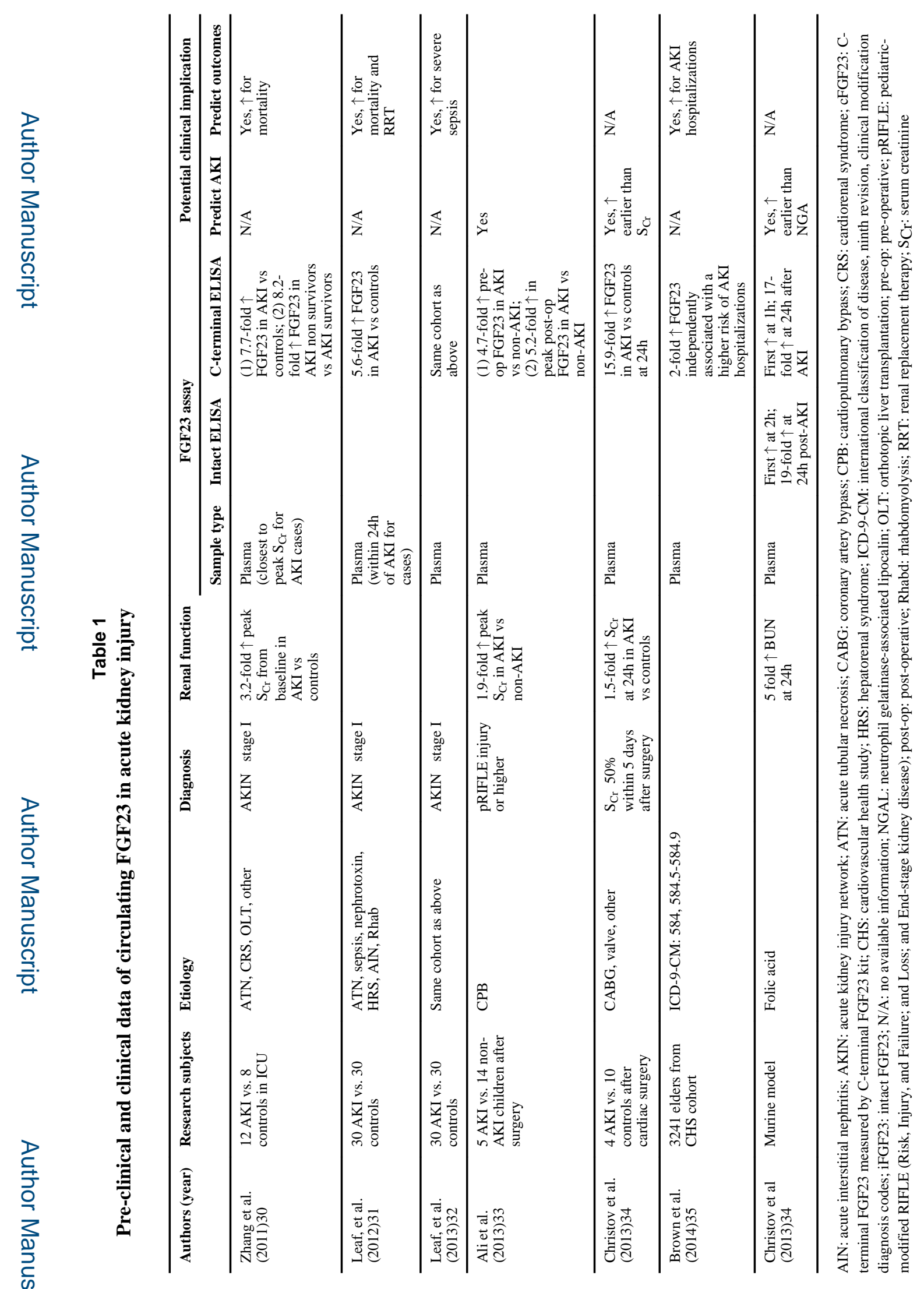

Pediatr Nephrol. Author manuscript; available in PMC 2016 November 01. 